\title{
CORRECTIONS
}

\section{Author Correction: Pre-eclampsia: pathogenesis, novel diagnostics and therapies}

Elizabeth A. Phipps, Ravi Thadhani, Thomas Benzing and S. Ananth Karumanchi@

Nature Reviews Nephrology (2019) https://doi.org/10.1038/s41581-019-0119-6

Published online 21 February 2019

In the version of this article originally published online, the date when Francois Mauriceau published one of the earliest descriptions of pre-eclampsia was incorrectly stated to be 1637 , which is actually his year of birth. The work was published in 1668. This error has been corrected in the PDF and HTML versions of the article.

https://doi.org/10.1038/s41581-019-0156-1 I Published online 8 May 2019 